\title{
Stage IVB Nasopharyngeal Carcinoma AJCC v8
}

National Cancer Institute

\section{Source}

National Cancer Institute. Stage IVB Nasopharyngeal Carcinoma A/CC v8. NCI

Thesaurus. Code C132822.

Stage IVB includes: Any T, Any N, M1. M1: Distant metastasis. (AJCC 8th ed.) 